\title{
Awareness of Golden Proportion in Tooth Forms Among Dental Students
}

\author{
Palak Mayur Shah ${ }^{1}$ and Dhanraj Ganapathy ${ }^{2}$ \\ ${ }^{1}$ Saveetha Dental College and hospitals, Saveetha Institute of Medical \\ and Technical Sciences, Saveetha University, Chennai, India \\ ${ }^{2}$ Professor and Head, Department of Prosthodontics, Saveetha Dental College and hospitals, \\ Saveetha Institute of Medical and Technical Sciences, Saveetha University, Chennai, India
}

\section{ABSTRACT}

An attractive smile is a key feature in maintaining and improving a person's esthetic appearance and, consequently, self-esteem. In addition, a smile has been described as one of the best methods to influence people. Even though societies dictate their own standards for beauty, meticulous analysis of attractive smiles has shown that repeatable, quantifiable, and unbiased principles can be methodically applied to assess and improve dental esthetics in predictable ways. The aim of this study was to evaluate the awareness regarding golden proportion among students of Saveetha Dental College and Hospitals. A structured questionnaire was given out to 100 randomly selected dental students of Saveetha dental college and hospitals, Chennai during December, 2019. Their responses were recorded manually. The questionnaire had questions regarding the golden proportion, ratio, importance in smile designing, etc. During the survey it was found that $79.2 \%$ of the students considered a smile of a patient to be very important. Keeping that in mind it was found that around 72.3\% of the students knew about the golden proportion rule of teeth. Around $60.4 \%$ of the students were correct to answer 1:618 as the GP ratio. From the entire group around $80.4 \%$ told that GP rule is used to design smiles and around $62.4 \%$ answered for rotation, crowding or spacing being the reason that affected the golden proportion of tooth. For the instrument used in measuring the GP ratio $71.3 \%$ of the students voted for vernier callipers to be the reason. According to the survey, the students

\section{INTRODUCTION}

Dental esthetics is a primary consideration for patients. New materials for dentistry and techniques were introduced maximizing the likelihood of an attractive outcome. The size and shape of the maxillary anterior teeth are important not only to dental esthetics, but also to facial esthetics. The principles that make up esthetics are subtle. Methodical analysis has revealed that principles can be applied to evaluate and alter

\section{ARTICLE INFORMATION}

*Corresponding Author: dhanraj@saveetha.com

Received 13th June 2020 Accepted after revision 4th August 2020

Print ISSN: 0974-6455 Online ISSN: 2321-4007 CODEN: BBRCBA

Thomson Reuters ISI Web of Science Clarivate Analytics USA and Crossref Indexed Journal

\section{Clarivate}

NAAS Journal Score 2020 (4.31) SJIF: 2020 (7.728)

A Society of Science and Nature Publication,

Bhopal India 2020. All rights reserved.

Online Contents Available at: http//www.bbrc.in/

Doi: http://dx.doi.org/10.21786/bbrc/13.7/56 dental esthetics with predictability. Each principle can be considered, recognised, assessed and developed individually in aesthetic management.(Hasanreisoglu et al., 2005)(Chander, Kumar and Rangarajan, 2012) Among the esthetic principles, the proportion can be predicted with a formula that defines the ratio of the component from one constituent to the next.

The golden proportion $(1.618: 1.0)$ is a mathematically constant ratio that defines the dimensions between larger and a smaller length. This specific relation is unique, perfect, ideal, and desirable. One of the most important guidelines is golden standard value. (Ong, Brown and Richmond, 2006) According to this standard, the ideal width-to-height proportion of maxillary central incisor should be approximately 80\% width compared with height. A higher width/height ratio means a squarer

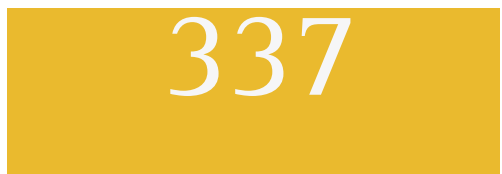


tooth, and a lower ratio indicates a longer appearance. It has been used from studying beauty to design esthetic restorations. (Wolfart et al., 2006).

According to Kanaparthy et.al, (Kanaparthy et al., 2016), to the Greeks the human body was based in mathematical proportions, which could be reproduced in artistic endeavours. To them, beauty was all about the details, mainly in the face. Always based on mathematical standards or references, the Greek built some of the most gorgeous and magnificent temples, such as Partenon and the most beautiful sculptures, such as Venus de Milo or Apollo of the Belvedere. These masterpieces were built following the Golden Ration principle. (Swileh, Abuaffan and Alhajj, 2019)

One of the critical aspects of esthetic dentistry is creating geometric or mathematical proportion to relate the successive width of anterior teeth. Golden proportion, golden percentage and recurring esthetic dental are theories introduced in this field. Ricketts was the first to suggest the application of the golden proportion in dentistry. He said that the golden proportion was 'too strong' for use in determining tooth size. He also described the use of a 'repeated ratio' in the maxillary anterior teeth. This implies that an optimized dentofacial composition of the lateral to central incisor width and the canine to lateral incisor width are repeated in proportion. (Ricketts, 1982)(Sarver and Ackerman, 2003)

Previously our department has published extensive research on various aspects of prosthetic dentistry ('Evaluation of Corrosive Behavior of Four Nickelchromium Alloys in Artificial Saliva by Cyclic Polarization Test:An in vitro Study', 2017; Ganapathy, Kannan and Venugopalan, 2017; Jain, 2017a, 2017b; Ranganathan, Ganapathy and Jain, 2017; Ariga et al., 2018; Gupta, Ariga and Deogade, 2018; Anbu et al., 2019; Ashok and Ganapathy, 2019; Duraisamy et al., 2019; Varghese, Ramesh and Veeraiyan, 2019), this vast research experience has inspired us to evaluate the awareness of golden proportion in tooth forms among the students of Saveetha dental college.

\section{MATERIAL AND METHODS}

This study was conducted via a questionnaire consisting of 10 multiple-choice questions. A questionnaire was formulated for the dental students, which included undergraduates and postgraduates to evaluate the awareness about Golden proportion in tooth form among students of Saveetha Dental College. This survey was taken in December 2019. The questionnaire consisted of questions regarding the golden proportion, golden proportion ratio, smile designing, golden proportion ratio in determination of the facial aspects and instrument used for measurement. This cross sectional questionnaire was conducted in the Department of Prosthodontics of Saveetha Dental College and Hospitals, Chennai. Inclusion criteria were dental students, undergraduates and postgraduates, students of Saveetha Dental college and subjects consented to participate. Students outside
Saveetha dental college, other medical students and patients unwilling to participate were excluded from the study.

\section{Questionnaire:}

1. How important is a smile for a patient?

a. Very important b) Moderately important c) Low importance

2. Have you heard of golden proportion for smile designing?

a. Yes b) No

3. What is the golden proportion in tooth forms?

a. Ration between 2 teeth b) Fraction between two teeth

4. What do you think is the GP ratio?

$\begin{array}{lll}\text { a. } 1: 212 & \text { b) } 1: 618 & \text { c) } 1: 445\end{array}$

5. Golden proportion helps in the determination of $?$

a. Aesthetics b)Facial form c)Size of tooth d) All of the above

6. Does golden proportion help design smiles?

$\begin{array}{llll}\text { a. Yes b) No c) I don't know } & \end{array}$

7. Does rotation, crowding or spacing affect the golden proportion?

a. Yes b) No c)I don't know

8. Do all age groups have the constant GP?

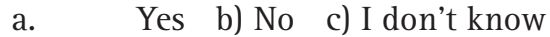

9. What can be used to calculate the GP?

a. Vernier calliper b) Scale c) Compass d) None of the above

10. WHich has the highest value?
a. Maxillary

Maxillary canine

\section{RESULTS AND DISCUSSION}

In the survey taken among the dental students of Saveetha Dental College, when asked about the importance of smile of a patient, around 79.2\% $(\mathrm{N}=80)$ voted for very important and around 13.9\% ( $\mathrm{N}=14)$ said it's moderately important. The rest 6.9\% $(\mathrm{N}=7)$ said it was less important. (Figure 1) When asked about the Golden proportion rule for smiles, around $72.3 \%(\mathrm{~N}=73)$ of the students knew about it and around 27.7\% $(\mathrm{N}=28)$ did not know about the rule. (Figure 2)

Figure 1: Bar chart represents the number of students to important of smile. $\mathrm{X}$ axis denotes the importance of smile and $Y$ axis denotes the number of students. Most of the students (79.2\%) opted for very important (green)

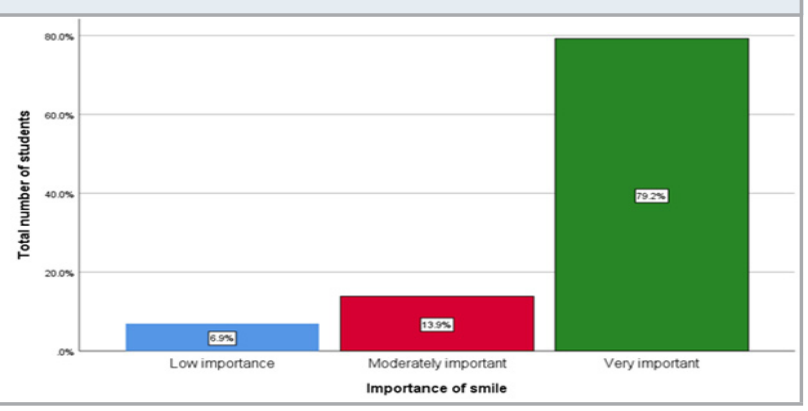


Figure 2: Bar chart represents the number of students if they have ever heard of golden proportion. $\mathrm{X}$ axis denotes the if they have ever heard of golden proportion and $Y$ axis denotes the number of students. Most of the students (72.3\%) opted for yes (red).

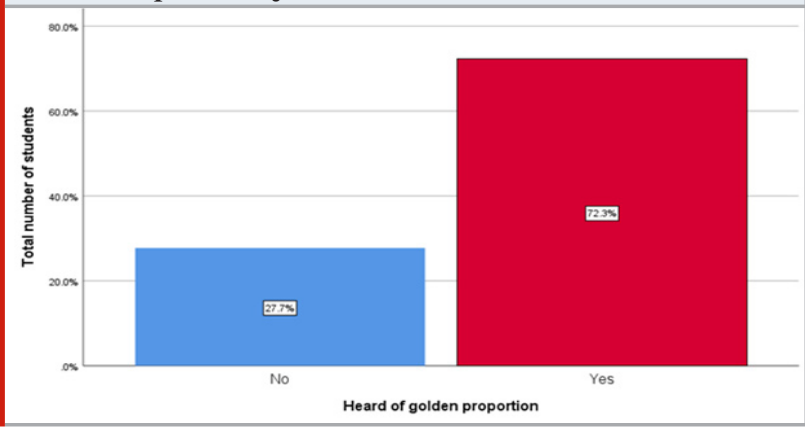

Figure 3: Bar chart represents the number of students to what they thought what golden proportion is. $\mathrm{X}$ axis denotes what golden proportion is and $\mathrm{Y}$ axis denotes the number of students. Most of the students (79.2\%) opted for a ratio between 2 teeth. (red)

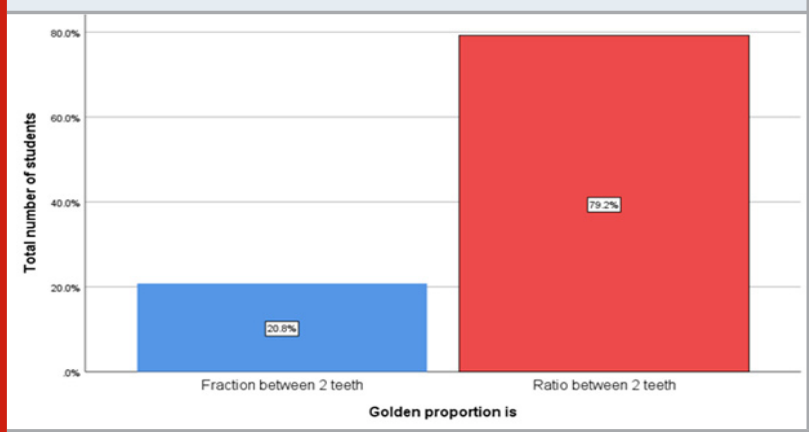

When asked what the golden proportion for tooth forms is, $79.2 \%(\mathrm{~N}=80)$ of the students answered the ratio between two teeth and $20.8 \%(\mathrm{~N}=21)$ replied the fraction between two teeth. (Figure 3) The students were asked about the GP ratio of a tooth and $60.4 \%(\mathrm{~N}=61)$ of the students voted for $1: 618$ and $27.7 \%(\mathrm{~N}=28)$ of the students voted for $1: 212$. The rest $11.9 \%(\mathrm{~N}=12)$ of the minority crowd voted for 1:445. (Figure 4) The students were asked whether Golden proportions help in determination of what aspect of the face. With options of Aesthetics, Facial form and Size of the tooth $69.4 \%(\mathrm{~N}=60)$ chose all of the above. $19.8 \%(\mathrm{~N}=20)$ chose Aesthetics, $15.8 \%$ $(\mathrm{N}=16)$ chose Facial form and $5 \%(\mathrm{~N}=5)$ chose Size of the tooth. (Figure 5)

When questioned if the golden proportion helped in designing smiles $80.2 \%(\mathrm{~N}=81)$ of them answered Yes, $11.9 \%(\mathrm{~N}=12)$ didn't know the answer and $7.9 \%(\mathrm{~N}=8)$ of them answered No. (Figure 6) When asked if rotation, crowding or spacing affected golden proportion, $62.4 \%(\mathrm{~N}=63)$ of them answered Yes $21.8 \%(\mathrm{~N}=22)$ of them answered No and the rest $15.8 \%(\mathrm{~N}=16)$ of them did not know the answer. (Figure 7) Around 49.5\%(N=50) of the students denied that all age groups have the same GP ratio and voted No. Roughly around $36.6 \%(\mathrm{~N}=37)$ voted
Yes and rest $13.9 \%(\mathrm{~N}=14)$ did not know the answer.. (Figure 8)

Figure 4: Bar chart represents the number of students to what they thought the GP ratio is. $\mathrm{X}$ axis denotes the GP ratio and $\mathrm{Y}$ axis denotes the number of students. Most of the students (60.4\%) opted for 1:618 (Red)

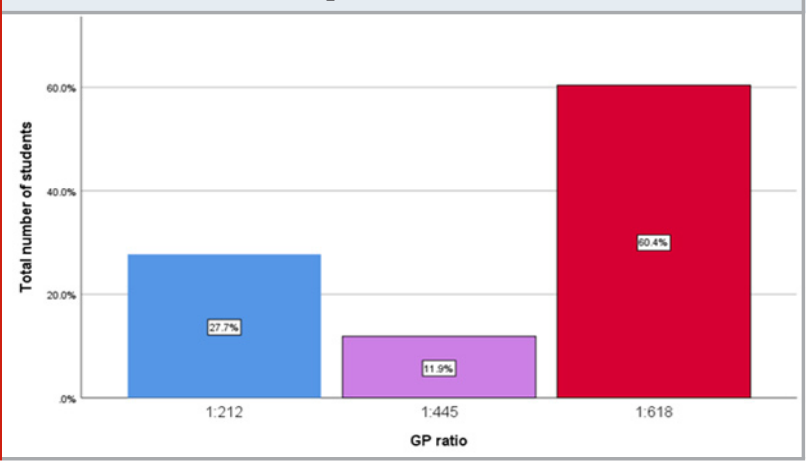

Figure 5: Bar chart represents the number of students to important of smile. $\mathrm{X}$ axis denotes the importance of smile and $Y$ axis denotes the number of students. Most of the students (79.2\%) opted for very important (green)

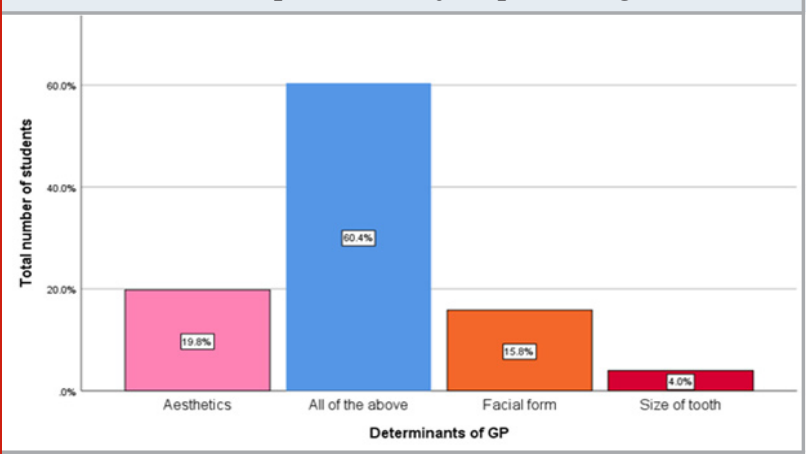

Figure 6: Bar chart represents the number of students and if GP helps in designing smiles. $\mathrm{X}$ axis denotes the does GP help in smile design and $Y$ axis denotes the number of students. Most of the students (80.2\%) opted for yes (Orange).

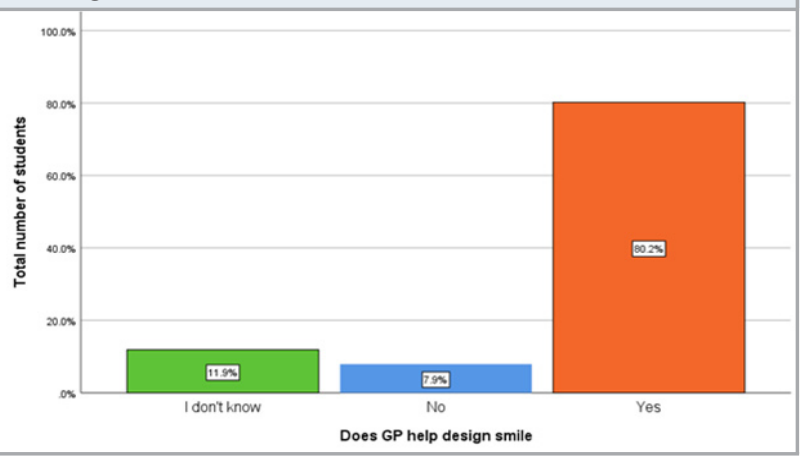

When asked about the instrument used to calculate the GP ratio $71.3 \%(\mathrm{~N}=72)$ voted for Vernier Calliper, $14.9 \%(\mathrm{~N}=15)$ voted for scale to be the instrument. The remaining 14 votes were divided equally between Compass at $6.9 \%(\mathrm{~N}=7)$ and none of the above also at $6.9 \%(n=7)$. (Figure 9) The students were asked about 
which tooth has the highest value and 73.3\%(N=74) voted for maxillary centrals, $15.8 \%(\mathrm{~N}=16)$ and the rest $10.9 \%$ $(\mathrm{N}=11)$ voted for maxillary canine. (Figure 10$)$

Figure 7: Bar chart represents the number of students to if rotation or crowding affects GP. $\mathrm{X}$ axis denotes the if rotating affects GP and $\mathrm{Y}$ axis denotes the number of students. Most of the students (79.2\%) opted for Yes (Purple).

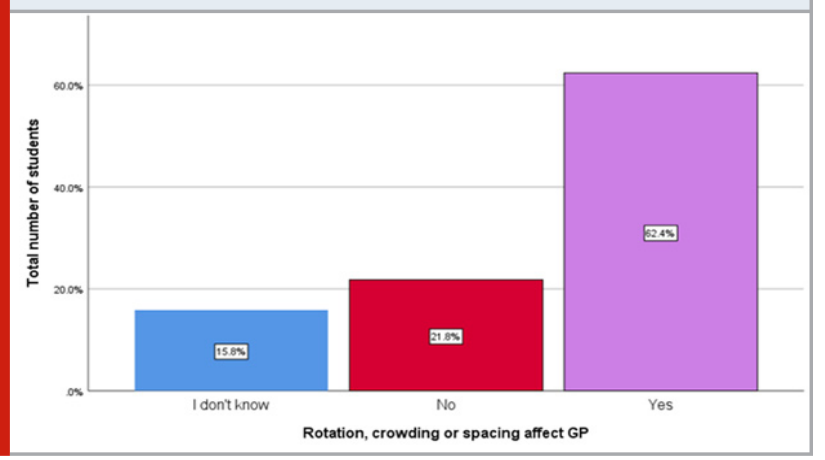

Figure 8: Bar chart represents the number of students to age having a constant GP. $\mathrm{X}$ axis denotes if age has a constant GP and $Y$ axis denotes the number of students. Most of the students (49.5\%) opted for No (red).

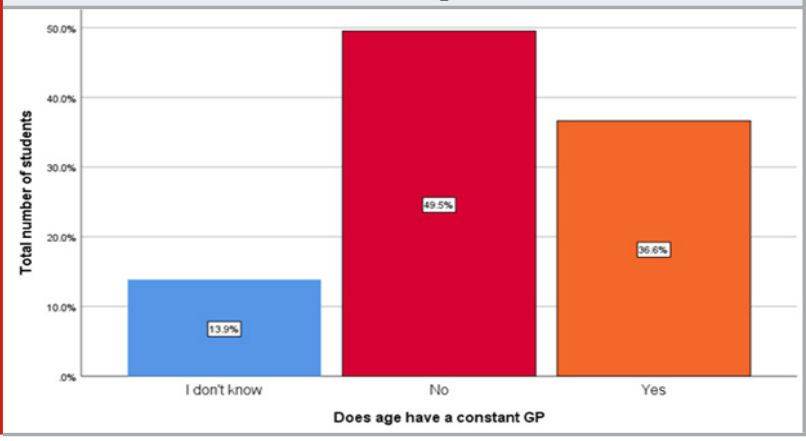

The golden proportion $(1.618: 1.0)$ describes the ratio between the dimensions of a larger and a smaller length. Various researchers have opined for and against the use of this mathematical proportions in dentistry. Levin observed the golden proportion between the width of the central incisor, lateral incisor and the canine. George and Bhatt found that the golden proportion is reliable predictors for determining the width of the maxillary central incisors in the south Indian population. Lombardi recommended a repeated ratio concept in contrast to golden proportion. Mahshid (Gillen et al., 1994) et al. reported that the golden proportion did not exist between the widths of the maxillary anterior teeth and it was substantiated by Ward, Gillen et al, Rosenstiel (Rosenstiel, Ward and Rashid, 2000) et al.The variation of thoughts among researchers and lack of similar study on Indian population aimed this study to evaluate the existence of golden proportion between anterior teeth in the Indian population.

Many dental and facial characteristics differ following the geographical location and historical background.
Figure 9: Bar chart represents the number of students the calculation of GP. $X$ axis denotes the calculation of GP and $\mathrm{Y}$ axis denotes the number of students. Most of the students (71.3\%) opted for vernier calliper (Red).

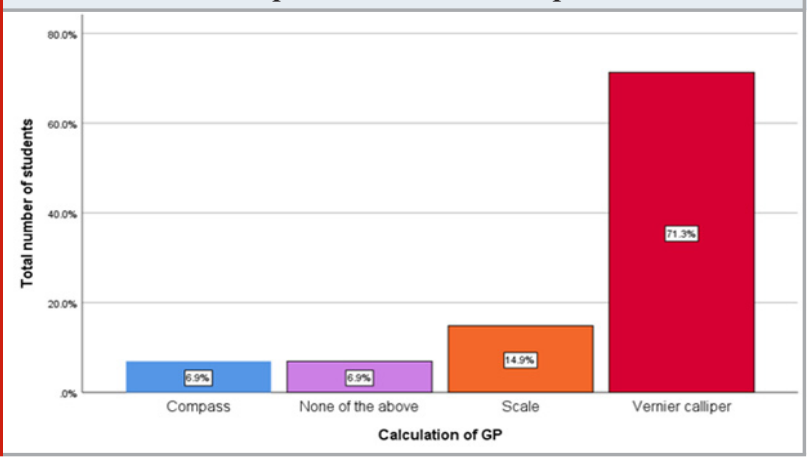

Figure 10: Bar chart represents the number of students to which tooth has the highest GP ratio. $\mathrm{X}$ axis denotes the tooth having the highest GP and $\mathrm{Y}$ axis denotes the number of students. Most of the students (73.3\%) opted for Maxillary centrals (Orange).

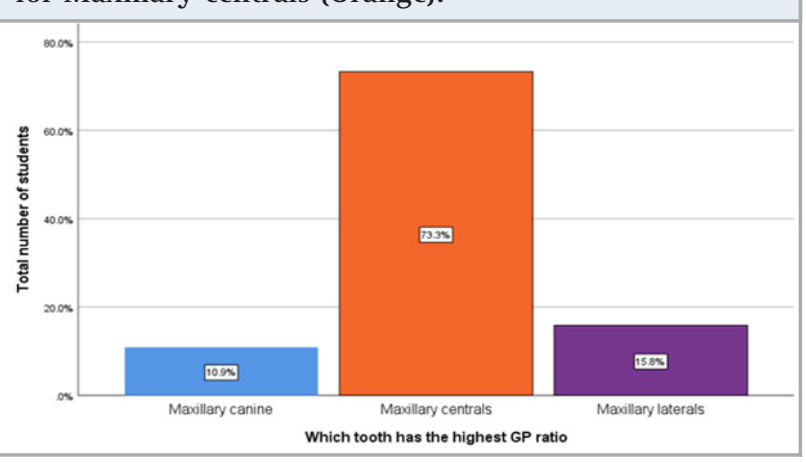

Therefore, information regarding tooth norms in a group of population is useful to dentists when restoring teeth. (Levin, 1978) The general Malaysian data can be used in the current study to compare with other populations as the golden proportion and golden standard was not found in all ethnic groups.Determination of a mathematical or geometrical relation between anterior teeth is important to achieve an esthetic result. It would be helpful if statistically reliable results existed to support existing theories. However, the golden proportion idea can no longer be considered since many articles found that golden proportion didn’t exist. (Snow, 1999)(Mahshid et al., 2004)

The results for Malaysian population were comparable to the results reported in similar studies of other populations, including Turkish, Iranians, Jordanians, Americans, Indians and Caucasians. Fayyad et al. (Fayyad, Jamani and Aqrabawi, 2006) reported that the ideal $\mathrm{W} / \mathrm{H}$ ratio for the central incisor should lie between 75 and 80\%. However, the ratio which allows an aesthetically acceptable appearance is in the 65 to $85 \%$ range.

According to Ricketts et al.,(Ricketts, 1982) the highest $\mathrm{W} / \mathrm{H}$ ratio is found in squarer teeth due to shorter height 
and/or greater width than those of other populations which came in agreement with the result of this study. The mean width to height ratio for the right lateral incisor of male patients involved in research is close to the golden proportion of 0.80. A Significant difference between the mean ratios of widths of maxillary anterior teeth compared with the ideal golden proportion for lateral to central incisor and between lateral incisor to canine was observed. Similarly, significant differences between mean $\mathrm{W} / \mathrm{H}$ ratios of lateral to central incisor and canine to lateral incisor and the golden proportion existed. Also, a significant difference in the mean values of the $\mathrm{W} / \mathrm{H}$ ratio for tooth number between males and females was seen. (Sarver and Ackerman, 2003)

\section{CONCLUSION}

The golden proportion is an element of design that a surgeon should be aware of. An understanding of this enigmatic proportion that has long stood for beauty may provide us with useful guidelines that can be combined with our existing knowledge and applied to our dental work for restoring dental esthetics with reasonable assurance of success. According to the survey, the students of Saveetha Dental College and Hospitals had adequate knowledge regarding the Golden proportion.

Authors Contributions: First author (Palak Mayur Shah) performed the analysis, and interpretation and wrote the manuscript. Second author (Dhanraj Ganapathy) contributed to conception, data design, analysis, interpretation and critically revised the manuscript. Both the authors have discussed the results and contributed to the final manuscript.

\section{Conflict of Interest: No conflict of interest.}

\section{REFERENCES}

Anbu, R. T. et al. (2019) 'Comparison of the Efficacy of Three Different Bone Regeneration Materials: An Animal Study', European journal of dentistry, 13(1), pp. 22-28.

Ariga, P. et al. (2018) 'Determination of Correlation of Width of Maxillary Anterior Teeth using Extraoral and Intraoral Factors in Indian Population: A Systematic Review', World Journal of Dentistry, 9(1), pp. 68-75.

Ashok, V. and Ganapathy, D. (2019) 'A geometrical method to classify face forms', Journal of oral biology and craniofacial research, 9(3), pp. 232-235.

Chander, N. G., Kumar, V. V. and Rangarajan, V. (2012) 'Golden proportion assessment between maxillary and mandibular teeth on Indian population', The journal of advanced prosthodontics, 4(2), pp. 72-75.

Duraisamy, R. et al. (2019) 'Compatibility of Nonoriginal Abutments With Implants: Evaluation of Microgap at the Implant-Abutment Interface, With Original and Nonoriginal Abutments', Implant dentistry, 28(3), pp. 289-295.
Evaluation of Corrosive Behavior of Four Nickelchromium Alloys in Artificial Saliva by Cyclic Polarization Test:An in vitro Study' (2017) World Journal of Dentistry, 8(6), pp. 477-482.

Fayyad, M. A., Jamani, K. D. and Aqrabawi, J. (2006) 'Geometric and Mathematical Proportions and their Relations to Maxillary Anterior Teeth', The Journal of Contemporary Dental Practice, pp. 62-70. doi: 10.5005/ jcdp-7-5-62.

Ganapathy, D. M., Kannan, A. and Venugopalan, S. (2017) 'Effect of Coated Surfaces influencing Screw Loosening in Implants: A Systematic Review and Meta-analysis', World Journal of Dentistry, 8(6), pp. 496-502.

Gillen, R. J. et al. (1994) 'An analysis of selected normative tooth proportions', The International journal of prosthodontics, 7(5), pp. 410-417.

Gupta, P., Ariga, P. and Deogade, S. C. (2018) 'Effect of Monopoly-coating Agent on the Surface Roughness of a Tissue Conditioner Subjected to Cleansing and Disinfection: A Contact Profilometric Study', Contemporary clinical dentistry, 9(Suppl 1), pp. S122S126.

Hasanreisoglu, U. et al. (2005) 'An analysis of maxillary anterior teeth: Facial and dental proportions', The Journal of Prosthetic Dentistry, pp. 530-538. doi: 10.1016/j.prosdent.2005.10.007.

Jain, A. R. (2017a) 'Clinical and Functional Outcomes of Implant Prostheses in Fibula Free Flaps', World Journal of Dentistry, 8(3), pp. 171-176.

Jain, A. R. (2017b) 'Prevalence of Partial Edentulousness and Treatment needs in Rural Population of South India', World Journal of Dentistry, 8(3), pp. 213-217.

Kanaparthy, A. et al. (2016) 'Evaluation of widths of maxillary anterior teeth and their relation to the golden proportion in the southwestern part of Saudi Arabia', Journal of Research in Medical and Dental Science, p. 83. doi: $10.5455 /$ jrmds.2016422.

Levin, E. I. (1978) 'Dental esthetics and the golden proportion', The Journal of Prosthetic Dentistry, pp. 244-252. doi: 10.1016/0022-3913(78)90028-8.

Mahshid, M. et al. (2004) 'Evaluation of "Golden Proportion" in Individuals with an Esthetic Smile', Journal of Esthetic and Restorative Dentistry, pp. 185-192. doi: 10.1111/j.1708-8240.2004.tb00032.x.

Ong, E., Brown, R. A. and Richmond, S. (2006) 'Peer assessment of dental attractiveness', American Journal of Orthodontics and Dentofacial Orthopedics, pp. 163-169. doi: 10.1016/j.ajodo.2005.02.018.

Ranganathan, H., Ganapathy, D. M. and Jain, A. R. (2017) 'Cervical and Incisal Marginal Discrepancy in Ceramic Laminate Veneering Materials: A SEM Analysis', Contemporary clinical dentistry, 8(2), pp. 
272-278.

Ricketts, R. M. (1982) 'The biologic significance of the divine proportion and Fibonacci series', American Journal of Orthodontics, pp. 351-370. doi: 10.1016/00029416(82)90073-2.

Rosenstiel, S. F., Ward, D. H. and Rashid, R. G. (2000) 'Dentists' preferences of anterior tooth proportion-a Web-based study', Journal of Prosthodontics, pp. 123-136. doi: 10.1053/jopr.2000.19987.

Sarver, D. M. and Ackerman, M. B. (2003) 'Dynamic smile visualization and quantification: part 2. smile analysis and treatment strategies', American Journal of Orthodontics and Dentofacial Orthopedics, pp. 116-127. doi: 10.1016/s0889-5406(03)00307-x.

Snow, S. R. (1999) 'Esthetic smile analysis of maxillary anterior tooth width: the golden percentage', Journal of esthetic dentistry, 11(4), pp. 177-184.

Swileh, M. A., Abuaffan, A. H. and Alhajj, M. N. (2019) 'Evaluation of the golden proportion and golden standard of maxillary anterior teeth in relation to smile attractiveness', Brazilian Dental Science, pp. 178-189. doi: 10.14295/bds.2019.v22i2.1694.

Varghese, S. S., Ramesh, A. and Veeraiyan, D. N. (2019) 'Blended Module-Based Teaching in Biostatistics and Research Methodology: A Retrospective Study with Postgraduate Dental Students', Journal of dental education, 83(4), pp. 445-450.

Wolfart, S. et al. (2006) 'Subjective and objective perception of upper incisors', Journal of Oral Rehabilitation, pp. 489-495. doi: 10.1111/j.13652842.2005.01581.x. 